\title{
Outcome of Methotrexate Management in Tubal Ectopic Pregnancy: A Retrospective Study in Women's Hospital in Qatar
}

\author{
${ }^{1} \mathrm{M}$ Gasim, ${ }^{2}$ Mohamed Diai, ${ }^{3}$ Mohammed Taha, ${ }^{4}$ Mona Alsaadi \\ ${ }^{5}$ Prem Chandra, ${ }^{6}$ Afif Mohamed, ${ }^{7}$ Arabo I Bayo, ${ }^{8}$ Badreldeen Ahmed
}

\begin{abstract}
Objective: Ectopic pregnancy case fatalities have decreased dramatically, although incidence has remained steady over years. Advancement in early diagnosis methods and introduction of methotrexate (MTX) in the management has led to such improvement. Different protocols, such as single, two dose and multiple doses of MTX has been indorsed by the American congress of obstetrics and gynecology. Here at Women's Hospital in Qatar we use single dose protocol. However, there no previous report on the outcome of MTX in term success rate in Qatar.
\end{abstract}

Methods: A retrospective study on patients diagnosed with tubal ectopic pregnancy between Jan 2008 and Dec 2010 were conducted. Institutional review board of Hamad Medical Corporation, Qatar, approved this study. Statistical analysis were done using SPSS Inc. Ver 20, Chicago, IL.

Results: Two hundred and forty-eight file met the study inclusion and exclusion criteria, but only 196 completed their followup until beta-human chorionic gonadotropin ( $\beta$-hCG) less than $15 \mathrm{IU} / \mathrm{L}$. Methotrexate prescribing has increased three times over the study period. The success rate for MTX was $89 \%$ and it was positively correlated with lower initial $\beta$-hCG levels. However, six out six patients with in $\beta$-hCG levels more than 10,000 IU/L were successfully treated with MTX.

Conclusion: Methotrexate is effective method of treatment in stable patients. Further studies are required to investigate role of MTX in patients with high $\beta$-hCG levels (> 10,000 IU/L).

Keywords: Ectopic pregnancy, Medical management, Methotrexate.

\footnotetext{
${ }^{1}$ Clinical Pharmacist and Visiting Researcher, ${ }^{2}$ Pharmacist ${ }^{3}$ Specialist, ${ }^{4}$ Assistant Director, ${ }^{5}$ Statistician, ${ }^{6}$ Clinical Pharmacy Specialist, ${ }^{7}$ Senior Consultant, ${ }^{8}$ Professor

${ }^{1}$ Department of Research, Weill Cornell Medical College in Qatar Doha, Qatar

${ }^{2,4,6}$ Department of Pharmacy, Women's Hospital, Doha, Qatar

3,7 Department of Obstetrics and Gynecology, Women's Hospital Doha, Qatar

${ }^{5}$ Medical Research Center, Hamad Medical Corporation, Doha Qatar

${ }^{8}$ Medical Education, Weill Cornell Medical College in Qatar Doha, Qatar
}

Corresponding Author: Badreldeen Ahmed, Professor, Medical Education, Weill Cornell Medical College, PO Box 34181, Doha Qatar, Phone: 0097455845583, e-mail: profbadreldeen@hotmail.com
How to cite this article: Gasim M, Diai M, Taha M, Alsaadi M, Chandra P, Mohamed A, Bayo AI, Ahmed B. Outcome of Methotrexate Management in Tubal Ectopic Pregnancy: A Retrospective Study in Women's Hospital in Qatar. Donald School J Ultrasound Obstet Gynecol 2015;9(2):118-122.

Source of support: Nil

Conflict of interest: None

\section{INTRODUCTION}

The last three decades have witnessed 6 fold increases in ectopic pregnancy rates (comprising $2 \%$ of all pregnancies), Nevertheless, there was a dramatic decrease in the case fatalities from 35.5 per 10,000 in 1970 s to 3.8 per $10,000{ }^{1,2}$ A progress that has been attributed to the introduction of early diagnosis with transvaginal ultrasound, serial $\beta-\mathrm{hCG}$, and the improvement in anesthesia field, antibiotics availability, blood transfusion and introduction of methotrexate (MTX) injection at the earliest 1970th. ${ }^{3,4}$ Moreover, introduction of medical management with MTX injection has improved posttreatment patient physical activity and decreased hospital stay and cost of treatment especially in patients with serum $\beta$-hCG $<1500$ IU/L. ${ }^{5,6}$

Different protocols have been developed since the introduction of MTX in the management of ectopic pregnancy. Stovall et al had demonstrated successful management with single dose MTX injection $\left(50 \mathrm{mg} / \mathrm{m}^{2}\right) .{ }^{5}$ Thereafter, international obstetric and gynecologic societies has adopted this protocol and recommended its use. ${ }^{7,8}$ While it has high success rate this protocol require the patient to have presented with unruptured ectopic pregnancy of a size $<3.5 \mathrm{~cm}, \beta-\mathrm{hCG}<5000 \mathrm{IU} / \mathrm{L}(\mathrm{RCOG})$ and 3500 IU/L (ACOG), hemodynamically stable with no known blood dyscariases, not known to have any chronic liver, renal and lung diseases and to be committed for followup as scheduled. If a patient fall in this criteria will be considered for MTX injection and will be followed by their $\beta$-hCG level on day 4,7 and then weekly. A decrease of $15 \%$ between any two points were deemed a positive marker, otherwise a second dose of MTX is prescribed if the patient is stable or will be posted for 
surgical intervention. Patients are considered successfully treated and discharged from follow-up when their $\beta$-hCG hormone become undetectable $(\beta-\mathrm{hCG}<5 \mathrm{IU} / \mathrm{L}){ }^{7,8}$

Methotrexate had been used for a long time in Women's Hospital in Qatar, and to date there is no study that has been conducted to find out the success rate of MTX injection when used for the management of ectopic pregnancy in Qatar population. Hence, we conducted a retrospective study in our institution.

\section{METHODS}

Ethical approval for this study was obtained from Medical Research Center, Hamad Medical Corporation, Qatar under research protocol number 11149/11.

We conducted a retrospective analysis of all women who received MTX for tubal ectopic pregnancy (EP) between Jan 2008 and Dec 2010. Patients excluded from the study were those with ectopic pregnancy of other locations and patients who received MTX for other reasons.

A list of the patients who received MTX during the study period was generated from the pharmacy management system, then patient's files were reviewed and screened for inclusion and exclusion criteria and data was recorded in a predesigned recording observation form. After data collection completion, random files were selected and reviewed by a second person (PI) to ensure correctness of recorded data on the data observation form in order to ensure validity of the read data values.

\section{Outcome Evaluation Criteria}

For the purpose of this study, the following were defined as:

- Baseline $\beta$-hCG: $\beta$-hCG level collected within 24 hours before MTX injection; any samples of $\beta$-hCG collected more than 24 hours prior to injection is considered as a missing value.

- Successful outcome: Follow-up until $\beta$-hCG become less than $15 \mathrm{IU} / \mathrm{L}$.

- Methotrexate dose (proper): $\mathrm{BSA}^{*} 50 \mathrm{~m}^{2} \pm 5 \mathrm{mg}$ (Based on our hospital administration protocol).

- BSA: Body surface area.

\section{Statistical Analysis}

Categorical and continuous data expressed as frequency (percentage) and mean \pm SD. Descriptive statistics used to summarize all demographic and clinical characteristics of the patients. Quantitative variables means between the two independent groups were analyzed using unpaired ' $t$ ' test. Changes in the mean scores for different quantitative variables at different time points were assessed and compared using repeated measure ANOVA. Pictorial presentations of the key results were made using appropriate statistical graphs. A two-sided p-value $<0.05$ was considered statistically significant. All statistical analyses were done using SPSS 19.0 (SPSS, Chicago).

\section{RESULTS}

We had 259 patients received MTX during the study period. Seven patients received MTX for other reasons and four files were not accessible. Therefore, 248 patients were included and their demographic data and clinical characteristics were tabulated (Flow Chart 1).

Majority of the patients were Qatari (34\%) followed by Indians (15\%). The gestational age at the time of diagnosis was 6 weeks (Table 1 ).

During our study period, MTX prescribing has increased 3 times in 2010 compared to 2008. Sixty percent of the patient received proper dose of MTX. In total, 79\% completed their follow-up. Mean baseline $\beta$-hCG level was $2486 \mathrm{IU} / \mathrm{L}$ ( $11 \%$ had baseline $\beta$-hCG between 3000 and $5000 \mathrm{IU} / \mathrm{L}$ and $14 \%$ of the patients had baseline $\beta$-hCG $\geq 5000 \mathrm{IU} / \mathrm{L}$ ). Of note, six patients received MTX with baseline $\beta$-hCG level > $10000 \mathrm{IU} / \mathrm{L}$.

Since, only 196 patients completed their follow-up. Subsequent analysis is based on these patients. Eightynine percent were successfully managed with MTX injection without further surgical intervention. Whilst $78 \%$ received one dose, $11 \%$ received two or three doses. All these were then followed until theirs $\beta$-hCG become $<15 \mathrm{IU} / \mathrm{L}$. The follow-up duration ranged between 1 and 4 months. Fifty percent of the patients had their $\beta$-hCG become $<15 \mathrm{IU} / \mathrm{L}$ in the first month and another $40 \%$ within 2 months. On the other hand, $11 \%$ of the patients started on MTX injection were treated surgically. Out of these, $72.2 \%$ had rupture, $16.7 \%$ had hormonal plateau and in $11.1 \%$ patients declined second dose of MTX.

Flow Chart 1: Patient inclusion: patient included in the final analysis $(n=196)$

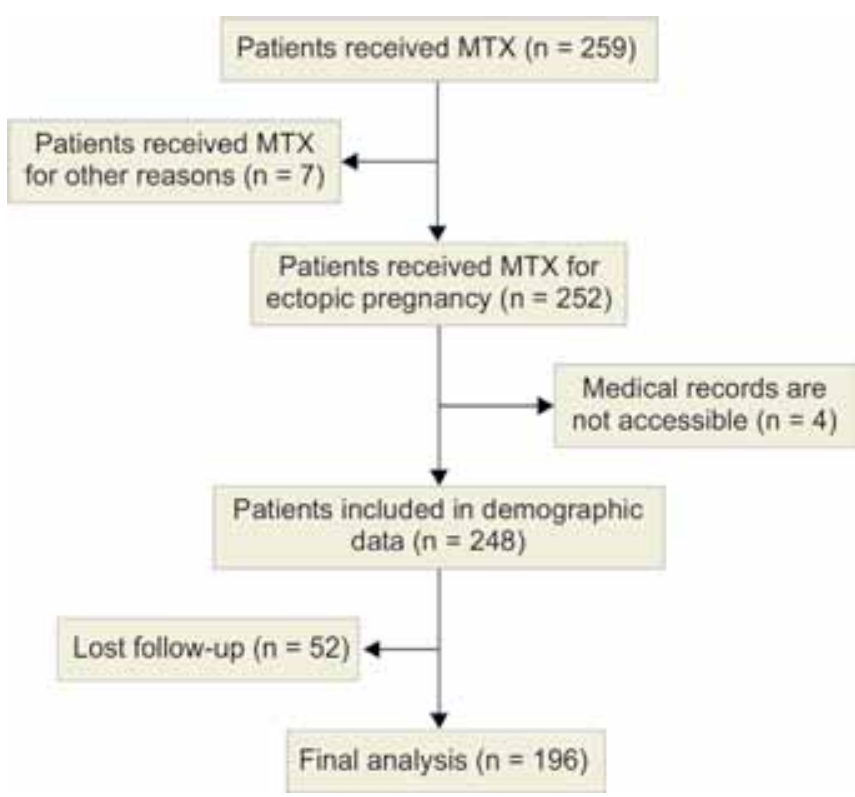


Table 1: Demographic data and clinical characteristic

\begin{tabular}{|c|c|c|c|}
\hline & $N$ & Mean (SD) & $\begin{array}{l}\text { Median } \\
\text { (range) }\end{array}$ \\
\hline Age (years) & 248 & $30(5)$ & $30(19-45)$ \\
\hline $\begin{array}{l}\text { Body surface } \\
\text { area }\left(\mathrm{m}^{2}\right)\end{array}$ & $245^{*}$ & $1.77(0.18)$ & $\begin{array}{l}1.7 \\
(1.28-2.25)\end{array}$ \\
\hline $\begin{array}{l}\text { Gestational age } \\
\text { (weeks) }\end{array}$ & $241^{*}$ & $6.0(2.0)$ & $\begin{array}{l}6.0 \\
(2.0-12.0)\end{array}$ \\
\hline $\begin{array}{l}\text { Baseline } \beta \text {-hCG } \\
\text { (IU/L) }\end{array}$ & $237^{*}$ & $\begin{array}{l}2486.15 \\
(3066.39)\end{array}$ & $\begin{array}{l}1542 \\
(38.0-20668.0)\end{array}$ \\
\hline $\begin{array}{l}\text { MTX dose } \\
\text { (calculated) (mg) }\end{array}$ & $245^{*}$ & $\begin{array}{l}85.47 \\
(8.83)\end{array}$ & $\begin{array}{l}84.8 \\
(63.9-112.7)\end{array}$ \\
\hline \multirow[t]{2}{*}{$\begin{array}{l}\text { MTX dose } \\
\text { (actual) }(\mathrm{mg})\end{array}$} & 248 & $90.0(12.0)$ & $\begin{array}{l}90 \\
(25-125)\end{array}$ \\
\hline & & $\begin{array}{l}\text { Frequency } \\
\text { (N) }\end{array}$ & Percentage \\
\hline \multicolumn{4}{|l|}{ Nationality* } \\
\hline & Qatari & 85 & 34.4 \\
\hline & Indian & 38 & 15.4 \\
\hline & Egyptian & 29 & 11.7 \\
\hline & Filipino & 15 & 6.1 \\
\hline & Jordan & 11 & 4.5 \\
\hline & Pakistani & 10 & 4.0 \\
\hline & Others & 59 & 23.9 \\
\hline \multicolumn{4}{|c|}{ Baseline $\beta-h C G$ group* } \\
\hline & $\begin{array}{l}<1000 \\
\mathrm{IU} / \mathrm{L}\end{array}$ & 87 & 34.5 \\
\hline & $\begin{array}{l}1001- \\
5000 \\
\text { IU/L }\end{array}$ & 115 & 45.6 \\
\hline & $\begin{array}{l}5001- \\
10000 \\
\text { IU/L }\end{array}$ & 27 & 10.7 \\
\hline & $\begin{array}{l}>10001 \\
\mathrm{IU} / \mathrm{L}\end{array}$ & 8 & 3.2 \\
\hline
\end{tabular}

*Patients number varies from total sample size represent missing values

Based on the treatment given, patients were further stratified into three groups; those who received one dose, those who received more than one dose and those who were treated with MTX and surgical intervention. Then, it was analyzed according to; $\beta$-hCG levels, MTX dose and patient compliance with follow-up.

Successful MTX outcome with single dose correlate positively with lower baseline level $\beta$-hCG $(p=0.003)$ (Table 2). Furthermore, patients who responded to one dose of MTX showed continues decline of $\beta$-hCG level over day 1, 4 and 7 (Graph 1). Higher number of patients had surgical removal of EP in the group who received high dose of MTX compared to patients who received proper dose ( $16.2 \%$ vs $8.8 \%$ ). There was a significant association between patient successful outcome and patient compliance to proper follow-up on day 4 and $7(p=0.034)$ (Table 2).

Where reduction in day 4 and $7 \beta$-hCG were $<15 \%$, $21 \%$ of the patient experienced medical treatment failure. While, a $15 \%$ decrease or more of $\beta$-hCG level between day 4 and 7 revealed $97 \%$ success rate (Graph 2).

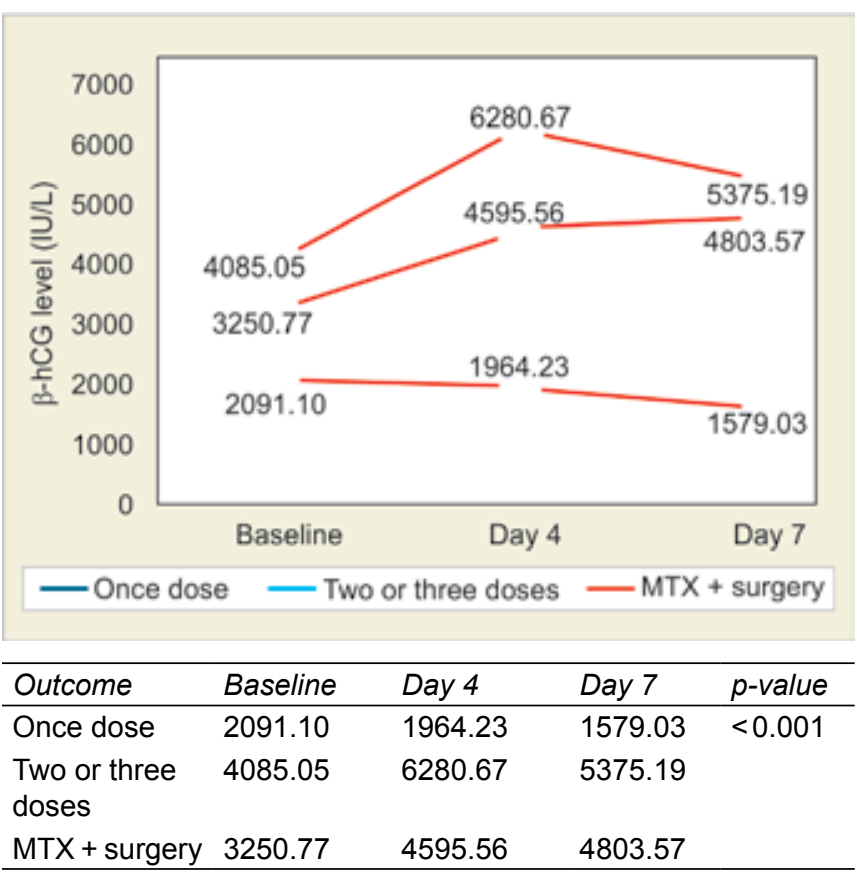

Graph 1: $\beta$-hCG level and patient outcome. ${ }^{*} p<0.001$ (association between baseline $\beta$-hCG and patient outcome) day 0/1 ( $\beta$-hCG0), day 4 ( $\beta$-hCG1) and day 7 ( $\beta$-hCG2)

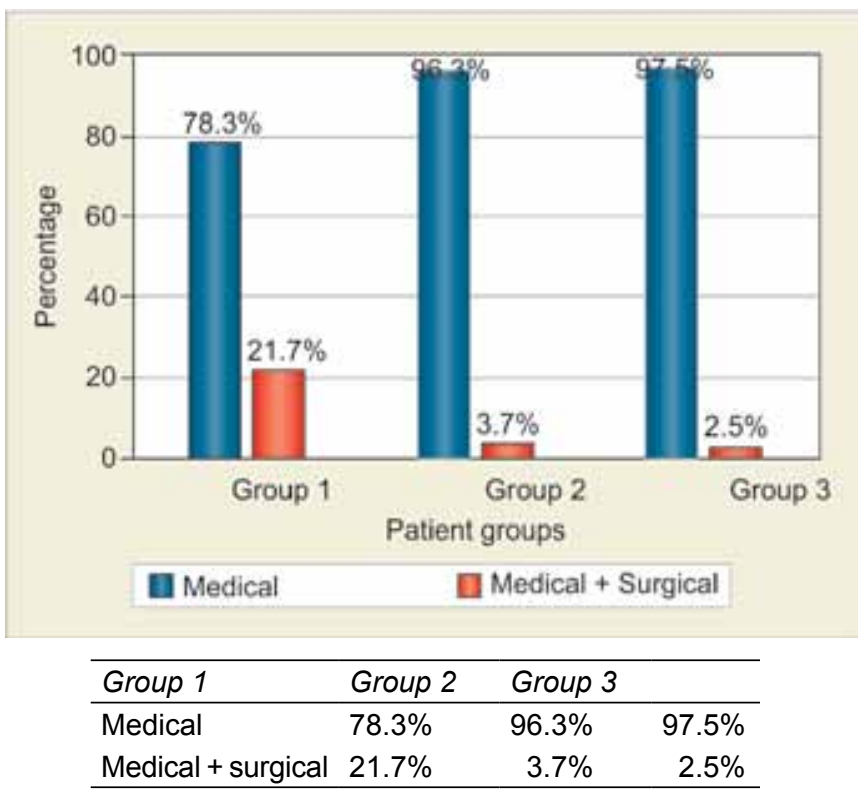

Graph 2: $\beta$-hCG decline between day 4 and 7 or day 1 and 4 as predictor for patient outcome. Group description: group 1: Decline in $\beta$-hCG in day 4 and $7<15 \%$, group 2: decline in $\beta$-hCG in day 1 and $4<15 \%$ and decline in $\beta$-hCG in day 4 and $7>15 \%$, group 3 : decline in $\beta-\mathrm{hCG}$ in day 1 and $4>15 \%$ and decline in $\beta$-hCG in day 4 and $7>15 \%$

\section{DISCUSSION}

Since, its introduction for management of EP, MTX use for EP is increasing worldwide. In a previous 6-year audit conducted by Cooray et al 2002 on MTX use for the management of EP, it was found that there is an increase use of MTX from 6 to $24 \% .^{9}$ Similarly, its use in our 
Table 2: Percentage of patient outcome base on baseline $\beta$-HCG

\begin{tabular}{|c|c|c|c|c|}
\hline & $N$ & $\begin{array}{l}\text { Successful } \\
N(\%)\end{array}$ & $\begin{array}{l}\text { Failure } \\
N(\%)\end{array}$ & $\begin{array}{l}p- \\
\text { value* }\end{array}$ \\
\hline \multicolumn{5}{|c|}{ Baseline $\beta-h C G$} \\
\hline$<1000$ & 75 & $72(96.0 \%)$ & $3(4.0 \%)$ & 0.003 \\
\hline $1001-5000$ & 88 & $76(86.4 \%)$ & $12(13.6 \%)$ & \\
\hline $5001-10000$ & 22 & $15(68.2 \%)$ & $7(31.8 \%)$ & \\
\hline$>10001$ & 6 & $6(100 \%)$ & $0(0.0 \%)$ & \\
\hline \multicolumn{5}{|c|}{ Dose appropriateness } \\
\hline Low dose & 10 & $10(90 \%)$ & $1(10 \%)$ & 0.313 \\
\hline Proper dose & 114 & $104(91.2 \%)$ & $10(8.8 \%)$ & \\
\hline High dose & 68 & $57(83.8 \%)$ & $11(16.2 \%)$ & \\
\hline \multicolumn{5}{|c|}{$\begin{array}{l}\text { Follow-up interval } \\
\text { between day } 4 \text { and } 7\end{array}$} \\
\hline Three days & 125 & $119(95.2)$ & $6(4.8 \%)$ & 0.034 \\
\hline Four days & 19 & $15(78.9)$ & $4(21.1 \%)$ & \\
\hline Others & 44 & $41(93.2)$ & $3(6.8 \%)$ & \\
\hline
\end{tabular}

${ }^{*}$ Chi-square test

hospital has increased. This is probably due to increase awareness of its use and confidence in its efficacy among physicians and minimal side effects encountered by the patients. Moreover, in our case, there is also an increase in total number of EP. Which might be due to the increase in the number of women at reproductive age. This can be deduce from the fact that Qatar has seen an increase number of birth rate per annum during this period.

A patient is deemed suitable for MTX injection if she met certain criteria such as; $\beta$-hCG $<5000 \mathrm{IU} / \mathrm{L}$, ectopic size $<3.5 \mathrm{~cm}$, absence of fetal heart beats, and clinically stable. ${ }^{7,8}$ Ectopic size $>3.5 \mathrm{~cm}$, initial $\beta$-hCG level $>5000 \mathrm{IU} / \mathrm{L}$ and fetal cardiac activity is considered a relative contraindications due to decreased success rate. ${ }^{10,11}$ However, in such situations the management was left to the physician's discern and patient's preference. Moreover, the cost between MTX therapy and laparoscopic surgery in patients with $\beta$-hCG below 1500 IU/L is comparable. ${ }^{12}$ Since, the cost is not an issue to the patient in our institution (because it is a public run service), few patients with relative contraindications opted for MTX management to avoid survey and to preserve future pregnancy.

We found higher number of patients who received high dose MTX end up with surgery. This might be because of presence of a relative contraindication, e.g. high $\beta$-hCG, large ectopic size and viable ectopic pregnancy rather than a response to high dose of MTX. Management of patients with such relative contraindications presents a hurdle to healthcare providers. However, increasing the dose - as seen in $35 \%$ of our patients - does not increase the success rate (Table 2). In the view of this, it is advisable to use a multiple dose regimen as recommended by. ${ }^{13}$
Comparing patients with $\beta$-hCG below $5000 \mathrm{IU} / \mathrm{L}$ in our study, we found similar success rate when compared to other studies. ${ }^{9,14,15}$ Interestingly, we found six out of six patients with high baseline $\beta$-hCG level (> $10000 \mathrm{IU} / \mathrm{L})$ were successfully managed with MTX alone, a result that might be a chance occurrence. However, in a systematic review that included a group of 22 patients with initial $\beta$-hCG > $10000 \mathrm{IU} / \mathrm{L}$ treated with MTX injection, $82 \%$ were successfully managed with the MTX only ${ }^{10}$ Gabor et al (2006) had also reported eight patients with a similar baseline $\beta$-hCG level after which six were successfully managed with MTX only. ${ }^{16}$ Further studies are required to investigate the role of MTX in this group of patients.

Follow-up after MTX injection is crucial. ${ }^{7} \beta$-hCG on days 4 and 7 is the cornerstone of follow-up. It can predict to high certainty if further intervention is required. We have shown a low success rate in patients with decline of $\leq 15 \%$ at days 4 and 7 compared to the other groups. Similarly, follow-up interval is important in predicting patient response. Loss of follow-up or inappropriate follow-up intervals represent a problem for healthcare providers, and patients may present with worsening clinical condition. Hence, compliance with follow-up is an integral part of the management.

\section{CONCLUSION AND RECOMMENDATION}

Methotrexate is an effective method of treatment for ectopic pregnancy in stable patients. Days 4 and $7 \beta$-hCG is the most indicative of MTX success. Our study also found that increasing the dose more than $50 \mathrm{mg} / \mathrm{m}^{2}$ does not improve patient's outcome in any of the patient categories. Methotrexate is also found to be effective in patient with baseline $\beta$-hCG $>10000 \mathrm{IU} / \mathrm{L}$, which has been contraindications to its use by many guidelines. Further studies is required to investigate the role of MTX in this group of patients. Strength of our study is a good number of patients reviewed, and generalizability of our study results on settings with the same practice and similar patient characteristics. On the other side, it is a retrospective data analysis. Hence, a larger number of patients will give a more robust data. Therefore, such a study is recommended.

\section{REFERENCES}

1. Goldner TE, Lawson HW, Xia Z, Atrash HK. Surveillance for ectopic pregnancy-United States, 1970-1989. MMWR CDC Surveill Summ 1993 Dec 17;42(6):73-85.

2. Saving Mothers' Lives: Reviewing maternal deaths to make motherhood safer: 2006-2008. BJOG: Int J Obstet Gynaecol 2011;118:1-203.

3. Stenchever MA. Comprehensive gynecology. 4th ed. St. Louis: Mosby; 2001.

4. Lipscomb GH. Medical therapy for ectopic pregnancy. Semin Reprod Med 2007 Mar;25(2):93-98. 
5. Stovall TG, Ling FW, Gray LA. Single-dose methotrexate for treatment of ectopic pregnancy. Obstet Gynecol 1991;77: 754-757.

6. Mol F, Mol BW, Ankum WM, van der Veen F, Hajenius PJ. Current evidence on surgery, systemic methotrexate and expectant management in the treatment of tubal ectopic pregnancy: a systematic review and meta-analysis. Hum Reprod Update 2008 Jul-Aug;14(4):309-319.

7. American College of Obstetricians and Gynecologists. ACOG Practice Bulletin No. 94: Medical management of ectopic pregnancy. Obstet Gynecol 2008 Jun;111(6):1479-1485.

8. Kelly AJ, Sowter MC, Trinder J. The management of tubal pregnancy. RCOG 2010.

9. Cooray H, Harilall M, Farquhar CM. A 6-year audit of the management of ectopic pregnancy. Aust N Z J Obstet Gynaecol 2002 Nov;42(5):538-542.

10. Menon S, Colins J, Barnhart KT. Establishing a human chorionic gonadotropin cutoff to guide methotrexate treatment of ectopic pregnancy: a systematic review. Fertil Steril 2007 Mar;87(3):481-484.

11. Lipscomb GH, McCord ML, Stovall TG, Huff G, Portera SG, Ling FW. Predictors of success of methotrexate treatment in women with tubal ectopic pregnancies. N Engl J Med 1999 Dec 23;341(26):1974-1978.

12. Sowter MC, Farquhar CM, Gudex G. An economic evaluation of single dose systemic methotrexate and laparoscopic surgery for the treatment of unruptured ectopic pregnancy. BJOG 2001 Feb;108(2):204-212.

13. Barnhart KT, Gosman G, Ashby R, Sammel M. The medical management of ectopic pregnancy: a meta-analysis comparing 'single dose' and 'multidose' regimens. Obstet Gynecol 2003 Apr;101(4):778-784.

14. Gungorduk K, Asicioglu O, Yildirim G, Gungorduk OC, Besimoglu B, Ark C. Comparison of single-dose and twodose methotrexate protocols for the treatment of unruptured ectopic pregnancy. J Obstet Gynaecol 2011 May;31(4):330-334.

15. Erdem M, Erdem A, Arslan M, Oc A, Biberoglu K, Gursoy R. Single-dose methotrexate for the treatment of unruptured ectopic pregnancy. Arch Gynecol Obstet 2004 Dec;270(4): 201-204.

16. Gabbur N, Sherer DM, Hellmann M, Abdelmalek E, Phillip P, Abulafia O. Do serum beta-human chorionic gonadotropin levels on day 4 following methotrexate treatment of patients with ectopic pregnancy predict successful single-dose therapy? Am J Perinatol 2006 Apr;23(3):193-196. 